\title{
Comparison of Two- and Three-dimensional Approaches for the Numerical Determination of Equivalent Mechanical Properties of Fractured Rock Masses
}

\author{
$\mathrm{Ki}-$ Bok Min ${ }^{1) *}$, Alain Thoraval ${ }^{2)}$
}

\section{균열암반의 역학적 등가물성의 수치해석적 결정을 위한 2차원 및 3 차원 해석의 비교}

민기복, 알렌토로발

\begin{abstract}
This paper compares the two- and three-dimensional (2D and 3D) approaches for the numerical determination of the equivalent mechanical properties of fractured rock masses. Both orthogonally-fractured model and discrete fracture networks (DFN) were used for the geometry and 2D models were cut in various directions from 3D model to compare their mechanical properties. Geological data were loosely based on the data available from Sellafield, UK. Analytical method based on compliance tensor transformation was used for investigation in orthogonally fractured rock and numerical experiments were conducted on fractured rock mass with DFN geometry. It is shown that $2 \mathrm{D}$ approach always overestimates the elastic modulus of fractured rock masses by a factor of up to around two because fractures are assumed to be perpendicular to the model plane in 2D problems. Poisson ratios tend to have larger values in $2 \mathrm{D}$ analysis while there is opposite trend in some sections. The study quantitatively demonstrates the limitation of the $2 \mathrm{D}$ approach that uses the simplified model from true 3D geometry.
\end{abstract}

Key words Discrete Element Method (DEM), Equivalent Mechanical Properties, Discrete Fracture Network (DFN), Rock Mass properties, Anisotropy

초 록 균열암반의 등가역학적 물성을 수치해석적으로 결정할 때 2 차원 및 3 차원 해석을 비교하였다. 수직균열 모델과 암반균열망(DFN) 모델이 균열암반의 형상으로 이용되었으며 3차원 모델으로부터 다양한 방향으로 2차 원 모델을 절단하여 역학적 물성을 비교하였다. 본 연구의 지질데이터는 영국 셀라필드 지역의 자료를 기본으로 사용하였다. 직교균열모델에서는 컴플라이언스텐서의 변환을 이용한 해석적 방법이 물성결정을 위해 이용되었 으며 암반균열망모델에서는 수치실험이 실시되었다. 2차원 모델에서는 균열이 항상 모델평면과 직교한다고 가 정하기 때문에 탄성계수는 항상 3 차원보다 크게 계산이 되었다. 2 차원 해석에서의 포아송비는 3 차원 해석보다 큰 값을 나타내는 경향이 있었으나 반대의 경향도 관찰되었다. 본 논문은 3 차원 형상을 단순화시켜 사용하는 2차원 해석의 한계를 정량적으로 고찰하였다는데 의의가 있다.

핵심어 개별요소법, 역학적 등가물성, 암반균열망, 암반의 물성, 이방성

1) 서울대학교에너지자원공학과

2) 프랑스국립산업환경연구원(INERIS)

* Coresponding Author: kbmin@snu.ac.kr Tel: +82-2-880-9074

Adress: Department of Energy Resources Engineering, Seoul National University, Seoul, Korea

Received: March 19, 2012

Revised: April 16, 2012

Accepted: April 17, 2012

\section{INTRODUCTION}

Determination of rock mass properties is an indispensible first step for any rock engineering analysis of civil, petroleum, mining or other geo-environmental applications where knowledge of the mechanical behaviour of rock mass is essential; however, determining the mechanical 
properties of rock mass has been a long-standing difficulty because the mechanical properties of rock that obtained from the laboratory differ from those of rock mass due to the presence of discontinuous fractures in the rock mass.

Rock mass properties are commonly determined by empirical methods, such as RMR, Q or GSI (Bieniawski, 1978; Barton, 2002; Hoek and Brown, 1997). Despite their practical usefulness, these methods are basically indirect methods, reflecting the fact that the direct measurement of the rock mass properties is difficult due to the largeness of scale in the order of more than a few meters and the control of boundary conditions. Major drawbacks of these empirical methods using rock mass classification include their inability to consider anisotropy and stress-dependency in addition to the subjective nature of their processes.

The idea of conducting 'numerical' experiments has been implemented with some success (Min and Jing, 2003). Compared to empirical methods, numerical experiments have some distinct advantages. The DFN-DEM (Discrete Fracture Network - Discrete Element Method) approach has been used as a numerical experiment, and this approach uses fracture system realizations as geometric models of the fractured rock masses and conducts numerical experiments using a DEM program, UDEC (Universal Distinct Element Codes, Itasca, 2000). Summary and discussion of these methods are presented in previous studies (Min and Jing, 2003; Min and Jing, 2004; Min and Stephansson, 2011).

The advantage of this DFN-DEM approach is that numerical experiments can be conducted multiple times with complete control of boundary conditions. This advantage puts us in a good position to consider the anisotropy and stress-dependency of fractured rock masses, both of which cannot be considered by empirical methods. Anisotropy can be significant because of the prevalent fractures that may contribute to the directional properties of fractured rock mass. Moreover, the mechanical properties of rock masses are dependent on the in situ stress, which is a direct function of depth. Martin et al. (2003) re-evaluated the extensometer results at the Olympic Ice Hockey Cavern in Gjøvik, Norway using a continuum model with equivalent rock mass modulus, and they showed that predictions of rock mass modulus from rock mass classification were far smaller than the measured results, and that accurate prediction was possible only when adjustments considering the nonlinear deformation of fractures were made. This stress-dependency of mechanical properties can be more effectively investigated by numerical experiments as shown in Min and Jing (2004).

These numerical experiments have been conducted in two and three dimensions (Min and Jing, 2003; Thoraval and Renaud, 2003). When it comes to the modeling of rock mass with numerous fractures, it should be noted that the geometry is simplified in this two-dimensional (2D) modeling and 2D analysis is a choice of compromise (Johansson et al., 1991). The fractures used in the 2D analysis are actually simplified to have strikes that are only normal to the model plane; however, there are more applications in 2D than in three dimensions (3D), which is mainly due to the lengthy computing time required for 3D computation. The two-dimensional approach has an advantage in terms of computing time, even with a relatively large number of fractures; however, it should be applied with the awareness of the limitations involved in the simplifications of fracture geometry. Indeed, the three-dimensional approach is more complete; however, it still has some limitations in terms of computing time when it involves large number of fractures. This aspect will hopefully be overcome in the near future.

To the authors' knowledge, a quantitative comparison of two- and three-dimensional approaches has not been conducted so far, and a more systematic comparison is necessary. The objective of this paper is therefore to compare the $2 \mathrm{D}$ and $3 \mathrm{D}$ approaches in order to evaluate the limitations of the $2 \mathrm{D}$ approach in terms of the numerical determination of the mechanical properties of a fractured rock mass.

\section{THEORY - CONSTITUTIVE EQUATION FOR MECHANICAL BEHAVIOR OF FRACTURED ROCK MASS}

The constitutive relation for general linear elasticity can be expressed as (Lekhnitskii, 1963; Min and Jing, 2003) 


$$
\varepsilon_{i j}=S_{i j k l} \sigma_{k l}
$$

where $\varepsilon_{i j}$ and $\sigma_{k l}$ are strain and stress tensors of a second-order rank, respectively, $S_{i j k l}$ is the compliance tensor of a fourth-order rank, involving 21 independent coefficients. By adopting a contracted matrix form of $S_{i j k l}$, Eq. (1) can be expressed as

$$
\left(\begin{array}{l}
\varepsilon_{x} \\
\varepsilon_{y} \\
\varepsilon_{z} \\
\gamma_{y z} \\
\gamma_{x z} \\
\gamma_{x y}
\end{array}\right)=\left(\begin{array}{llllll}
S_{11} & S_{12} & S_{13} & S_{14} & S_{15} & S_{16} \\
S_{21} & S_{22} & S_{23} & S_{24} & S_{25} & S_{26} \\
S_{31} & S_{32} & S_{33} & S_{34} & S_{35} & S_{36} \\
S_{41} & S_{42} & S_{43} & S_{44} & S_{45} & S_{46} \\
S_{51} & S_{52} & S_{53} & S_{54} & S_{55} & S_{56} \\
S_{61} & S_{62} & S_{63} & S_{64} & S_{65} & S_{66}
\end{array}\right)\left(\begin{array}{l}
\sigma_{x} \\
\sigma_{y} \\
\sigma_{z} \\
\tau_{y z} \\
\tau_{x z} \\
\tau_{x y}
\end{array}\right)
$$

where matrix $S_{i j}$ is called the 'compliance matrix' and the above equation is called 'generalized Hooke's law' (Lekhnitskii, 1963). The symbols $\mathcal{E}_{i}$ and $\gamma_{i j}(i, j=x$, $y, z$ ) denote the normal and shear strains, respectively, and symbols $\sigma_{i}$ and $\tau_{i j}(i, j=x, y, z)$ denote the normal and shear stresses, respectively. The compliance matrix can be described explicitly by giving the physical meaning of each element as combinations of elastic moduli, Poisson ratios, shear moduli and other technical constants of the solids.

When the compliance tensor is expressed in matrix form, following mapping operation with a 6-by-6 matrix is introduced in a simplified form (Lekhnitskii, 1963)

$$
S_{i j}^{\prime}=S_{m n} q_{m i} q_{n j}
$$

where $S_{i j}^{\prime}$ is the compliance matrix in the transformed axes and $S_{m n}$ is the compliance matrix in the original axes, respectively. The components of the $q_{i j}$ matrix are composed of directions and their combinations (Min and Jing, 2003).

In most practical cases, anisotropic rocks are modeled as orthotropic or transversely isotropic materials in a co-coordinate system attached to their directions of symmetry. A material that has three orthogonal planes of elastic symmetry at each point is called 'orthotropic' (Lekhnitskii, 1963). For orthotropic material, generalized Hooke's law Eq.(2) has the following form,

$$
\left(\begin{array}{c}
\varepsilon_{x} \\
\varepsilon_{y} \\
\varepsilon_{z} \\
\gamma_{y z} \\
\gamma_{x z} \\
\gamma_{x y}
\end{array}\right)=\left(\begin{array}{cccccc}
\frac{1}{E_{x}} & -\frac{v_{y x}}{E_{y}} & -\frac{v_{z x}}{E_{z}} & 0 & 0 & 0 \\
-\frac{v_{x y}}{E_{x}} & \frac{1}{E_{y}} & -\frac{v_{z y}}{E_{z}} & 0 & 0 & 0 \\
-\frac{v_{x z}}{E_{x}} & -\frac{v_{y z}}{E_{y}} & \frac{1}{E_{z}} & 0 & 0 & 0 \\
0 & 0 & 0 & \frac{1}{G_{y z}} & 0 & 0 \\
0 & 0 & 0 & 0 & \frac{1}{G_{x z}} & 0 \\
0 & 0 & 0 & 0 & 0 & \frac{1}{G_{x y}}
\end{array}\right)\left(\begin{array}{c}
\sigma_{x} \\
\sigma_{y} \\
\sigma_{z} \\
\tau_{y z} \\
\tau_{x z} \\
\tau_{x y}
\end{array}\right)
$$

Where $E_{x}, E_{y}$ and $E_{z}$ are the elastic moduli with respect to directions $x, y$, and $z$, respectively. $G_{y z}, G_{z x}$ and $G_{x y}$ are the shear moduli for elastic symmetry planes, which are parallel to the $y z, z x$, and $x y$ planes, respectively. The Poisson's ratios $v_{i j}$ determines the ratio of strain in the $j$ direction to the strain in the $i$ direction due to a stress acting in the $i$ direction.

The compliance tensor of a rock mass with three sets of orthogonal persistent fractures in threedimension (Figure 1) is constructed by superimposing the fracture constitutive relations on the compliance matrix of intact rock, by treating the rock mass as an orthotropic elastic material (Amadei and Goodman, 1981; Min and Jing, 2003).

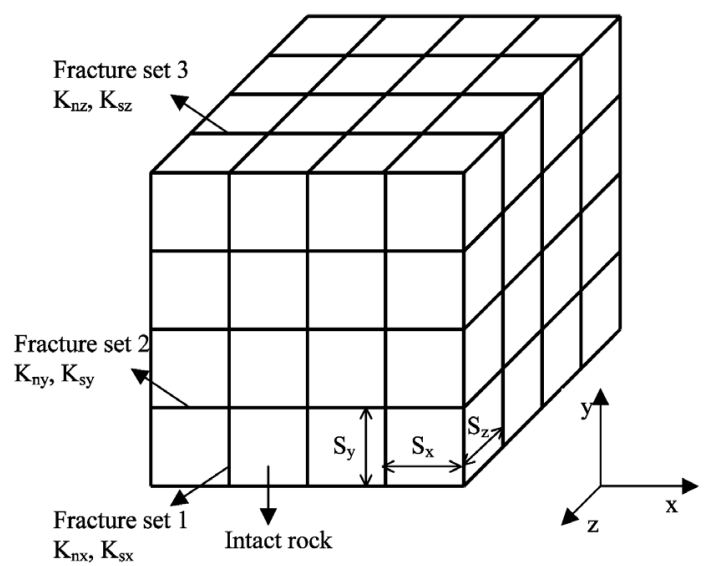

Fig. 1. Simplified diagram for the reference axes and rock blocks. Explanations of parameters are given in the text (Min and Jing, 2003) 


\section{METHODOLOGY- NUMERICAL EXPERIMENTS IN TWO AND THREE DIMENSIONS}

A new upscaling method has been proposed to determine the equivalent mechanical properties of a fractured rockmass. This method is based on the $2 \mathrm{D}$ or $3 \mathrm{D}$ numerical simulations of the behaviour of a "sample" of fractured rockmass subjected to different mechanical boundary conditions. The simulations are defined in order to determine the equivalent compliance tensor of a fractured rockmass. RESOBLOK (Heliot, 1988) was used to generate the $3 \mathrm{D}$ fracture network or $2 \mathrm{D}$ fracture network on cross-sections, and UDEC and 3DEC (Itasca Consulting Group, 1994; Damjanac, 1994) were used to make the mechanical computations in $2 \mathrm{D}$ and $3 \mathrm{D}$, respectively (Figure 2).

\subsection{Generation of the fracture network}

The fracture geometries chosen for this study were of two types - orthogonally fractured rock masses with persistent fractures and discrete fracture network (DFN) models generated by Monte Carlo simulation. Geological data used for the DFN models are loosely based on the site investigation at Sellafield undertaken by Nirex, UK. A realistic fracture network is generated using DFN generator, RESOBLOK (Heliot, 1988), and its geometry is passed on to UDEC/3DEC (Universal Distinct Element Method Codes in 2D and 3D) for the calculation of equivalent properties in fractured rock masses.
For the orthogonally fractured rock masses, a mechanical compliance tensor can be determined by the analytical solution, and the comparison can be readily made. This investigation of the simple orthogonal model can provide insight into the investigation of more complex DFN models.

For the DFN models, a series of $2 \mathrm{D}$ sections is cut along the 3D DFN models and equivalent properties in 2D sections and 3D DFN models are compared. Compliance tensors of $2 \mathrm{D}$ sections vary along the cross-sections. The code used to generate the fracture network (RESOBLOK) is based on the assumption that the fracture can be considered as a polygon. This code is able to make deterministic or stochastic simulations.

The following assumptions are made in terms of fracture statistics. Fracture density (i.e., number of fractures per unit volume of rock $-\mathrm{P}_{31}$ ) is assumed to follow Poisson's law. Fracture orientation is assumed to follow Fisher distribution. Average dip and dip direction, as well as the Fisher coefficient, have to be given for the different fracture sets. Fracture length is assumed to follow a power law distribution of the form $\mathrm{N}=\mathrm{CL}^{-\mathrm{D}}$, where $\mathrm{N}$ is the number of fractures that are equal to or greater than a given trace length L, D is the fractal dimension, and $\mathrm{C}$ is a constant. Figure 3 shows the parent 3D DFN model used for this study.

A specific command of RESOBLOK is used to generate a $3 \mathrm{DEC}$ file that includes all information regarding fracture network geometry. 3DEC does not allow the generation of the fractures that stop inside a block. During the 3DEC cutting process, the plane where the

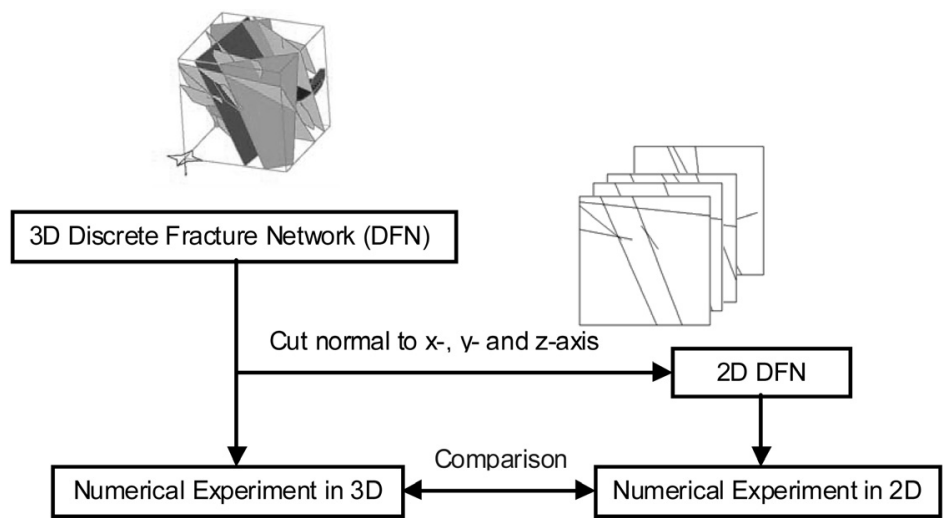

Fig. 2. Methodology for the comparison of $2 \mathrm{D}$ and $3 \mathrm{D}$ approach 


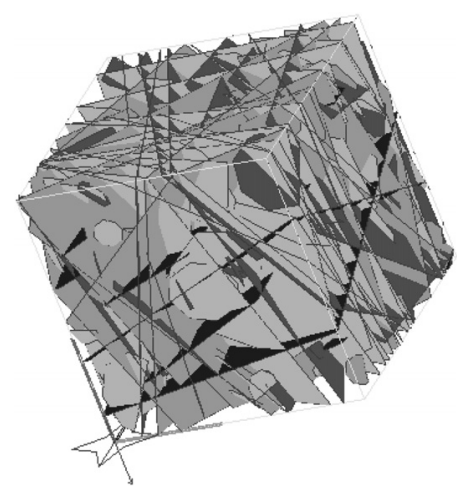

(a)

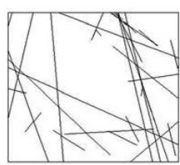

$0.0 \mathrm{~m}$

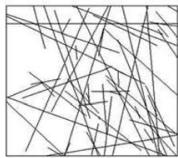

$3.0 \mathrm{~m}$

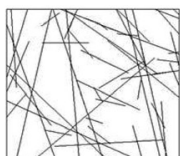

$0.5 \mathrm{~m}$

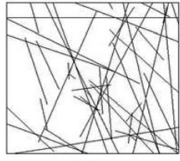

$3.5 \mathrm{~m}$

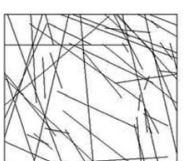

$1.0 \mathrm{~m}$

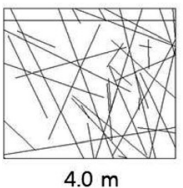

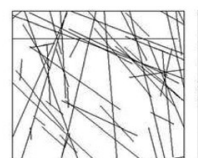

$1.5 \mathrm{~m}$

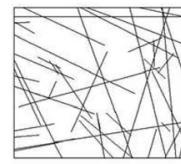

$4.5 \mathrm{~m}$

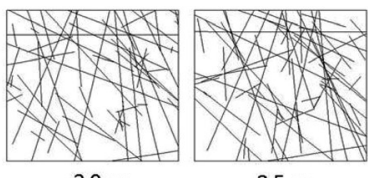

$2.0 \mathrm{~m}$

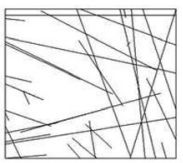

$5.0 \mathrm{~m}$

(b)
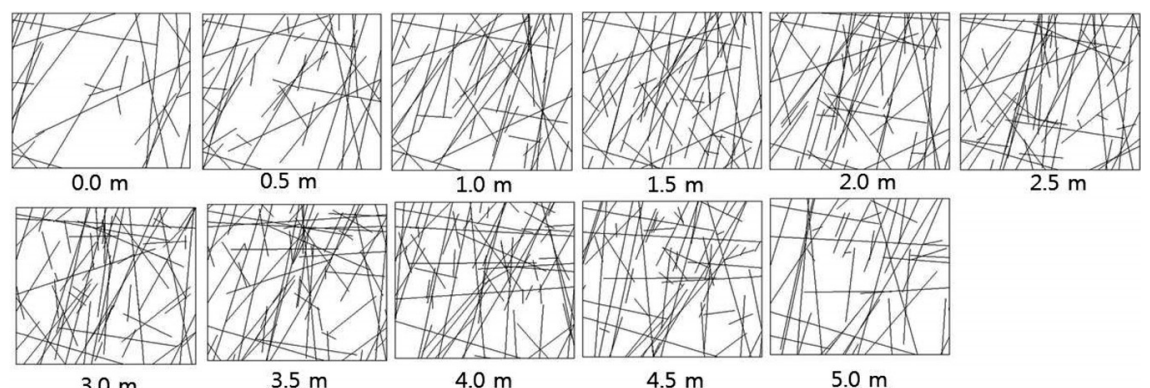

$3.0 \mathrm{~m}$

$4.0 \mathrm{~m}$

$4.5 \mathrm{~m}$

$5.0 \mathrm{~m}$

(c)
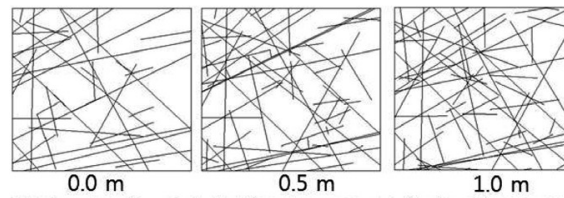

$1.0 \mathrm{~m}$
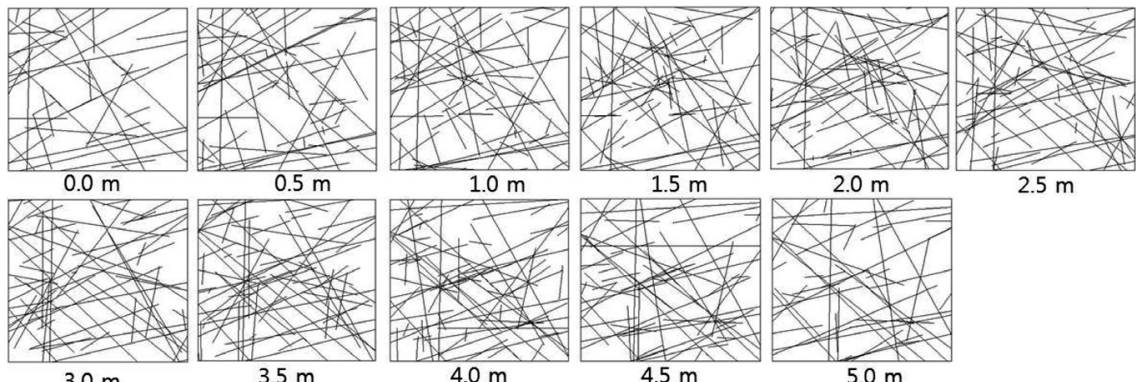

(d)

Fig. 3. 3D and 2D Discrete Fracture Networks generated by RESOBLOK. The side length of the model sare $5 \mathrm{~m}$. (a) 3D DFN model, (b) 2D DFN models cut along and normal to x-axis, (c) 2D DFN models cut along and normal to y-axis, (d) 2D DFN models cut along and normal to z-axis. The cut section coordinate sare shown below the 2D DFN models 
RESOBLOK polygonal fracture is lying is continued up to the next fracture (or block face); however, 3DEC automatically distinguishes 2 zones (from information output from RESOBLOK): an active zone inside the polygon area (real joint) and an inactive zone outside the polygon (fictitious joint). So, 3DEC is able to give different properties to real joints and fictitious joints.

2D fracture networks corresponding to the intersection of the 3D fracture network were generated with a given cross-section. For the purpose of comparing 2D and $3 \mathrm{D}$, eleven cross-sections were cut in each of the three orthogonal directions.

\subsection{Numerical experiments for mechanical compliance tensor}

To determine all of the tensor terms with 3DEC, six sets of boundary conditions have to be applied (Figure 4). For normal stress change (Figure 4 (a)), an initial state of stress $\left(\sigma=10^{6} \mathrm{~Pa}\right)$ is applied to the model, and a constant stress increment $\left(\Delta \sigma=10^{5} \mathrm{~Pa}\right)$ is applied on the grey faces. For shear stress change (Figure 4 (b), an initial state of stress $\left(\sigma=10^{6} \mathrm{~Pa}\right)$ is applied to the model and a constant stress increment $\left(\Delta \tau=10^{5}\right.$ $\mathrm{Pa})$ is applied on the grey faces. Figure 5 shows the boundary conditions for 2D approach and detailed explanation can be found in Min and Jing (2003).

During each 3DEC run, the average strain tensor is computed from displacement differences between opposite faces of the model and 100 pairs of points are used

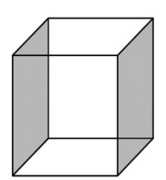

$\Delta \sigma \mathrm{x}=1 \mathrm{e} 5 \mathrm{~Pa}$

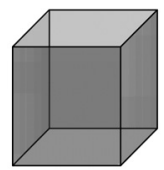

$\Delta \tau x y=1 e 5 \mathrm{~Pa}$

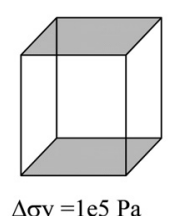

(a)

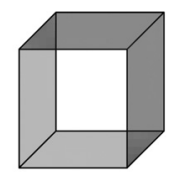

$\Delta \tau \mathrm{xz}=1 \mathrm{e} 5 \mathrm{~Pa}$

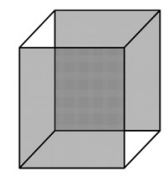

$\Delta \sigma \mathrm{z}=1 \mathrm{e} 5 \mathrm{~Pa}$
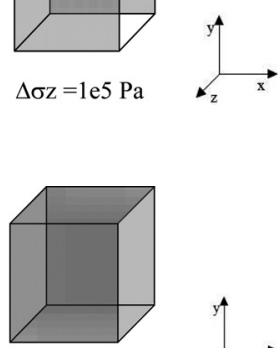

$\Delta \tau \mathrm{yz}=1 \mathrm{e} 5 \mathrm{~Pa}$

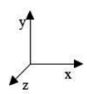

(b)

Fig. 4. Six linearly independent boundary conditions for 3D computations. (a) normal stresses. (b) shear stresses for each strain term.

In order to calculate the 21 independent component of compliance matrix or stiffness matrix, we need six set of boundary conditions. When six sets of boundary conditions are imposed and counterpart responses (i.e., stress when that strain boundary condition is applied and vice versa) are measured, the eq.(2) becomes as follows.

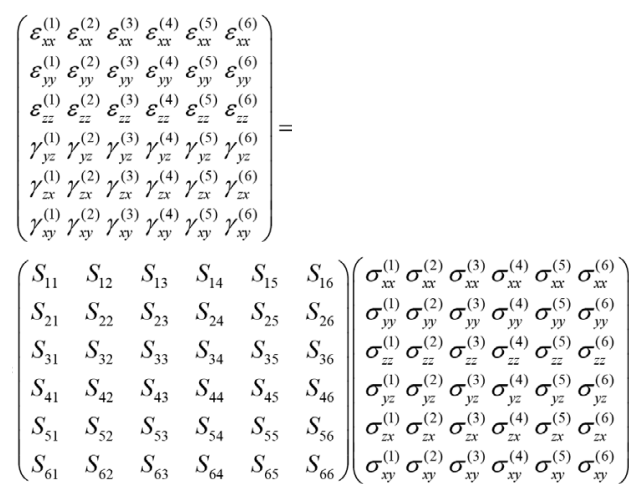

In other words,

$$
[\varepsilon]=[S][\sigma]
$$

Hence, the compliance matrix can be obtained as follows.

$$
[\varepsilon][\sigma]^{-1}=[S]
$$

The obtained compliance matrix must be symmetric, and asymmetric parts are considered to be related to numerical errors.

If we have more than 6 sets of boundary conditions, then we have more equations than unknowns, i.e., the

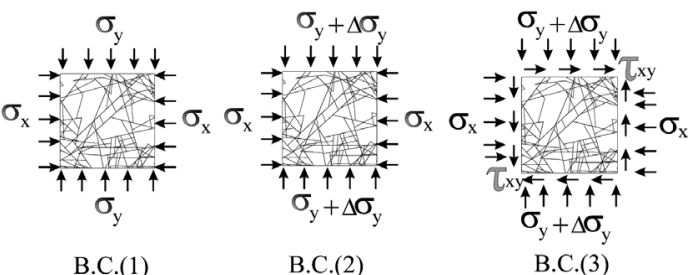

Fig. 5. Three linearly independent boundary conditions for 2D computations (Min and Jing, 2003) 
problem needs to be solved through the least square method. For that case, the following procedure is suggested.

$$
\begin{aligned}
& {[\varepsilon]=[S][\sigma]} \\
& {[\varepsilon][\sigma]^{T}=[S][\sigma][\sigma]^{T}} \\
& {[\varepsilon][\sigma]^{T}\left[[\sigma][\sigma]^{T}\right]^{-1}=[S]}
\end{aligned}
$$

For the case of two-dimensional plane strain condition, the following equations hold (Min and Stephansson, 2011).

$$
\left(\begin{array}{l}
\varepsilon_{x x} \\
\varepsilon_{y y} \\
\varepsilon_{z z} \\
\gamma_{x y}
\end{array}\right)=\left(\begin{array}{llll}
S_{11} & S_{12} & S_{13} & S_{16} \\
S_{21} & S_{22} & S_{23} & S_{26} \\
S_{31} & S_{32} & S_{33} & S_{36} \\
S_{61} & S_{62} & S_{63} & S_{66}
\end{array}\right)\left(\begin{array}{l}
\sigma_{x x} \\
\sigma_{y y} \\
\sigma_{z z} \\
\sigma_{x y}
\end{array}\right)
$$

where $\mathrm{S}_{13}\left(\mathrm{~S}_{31}\right), \mathrm{S}_{23}\left(\mathrm{~S}_{32}\right), \mathrm{S}_{33}$ and $\mathrm{S}_{63}$ are pre-determined by the geometry of the $2 \mathrm{D}$ sample.

$$
\begin{aligned}
& \left(\begin{array}{l}
\varepsilon_{x x} \\
\varepsilon_{y y} \\
\gamma_{x y}
\end{array}\right)=\left(\begin{array}{lll}
S_{11} & S_{12} & S_{16} \\
S_{21} & S_{22} & S_{26} \\
S_{61} & S_{62} & S_{66}
\end{array}\right)\left(\begin{array}{l}
\sigma_{x x} \\
\sigma_{y y} \\
\sigma_{x y}
\end{array}\right)+\left(\begin{array}{l}
S_{13} \\
S_{23} \\
S_{63}
\end{array}\right)\left(\sigma_{z z}\right) \\
& \left(\begin{array}{lll}
\varepsilon_{x x}^{(1)} & \varepsilon_{x x}^{(2)} & \varepsilon_{x x}^{(3)} \\
\varepsilon_{y y}^{(1)} & \varepsilon_{y y}^{(2)} & \varepsilon_{y y}^{(3)} \\
\gamma_{x y}^{(1)} & \gamma_{x y}^{(2)} & \gamma_{x y}^{(3)}
\end{array}\right)-\left(\begin{array}{l}
S_{13} \\
S_{23} \\
S_{63}
\end{array}\right)\left(\begin{array}{lll}
\sigma_{z z}^{(1)} & \sigma_{z z}^{(2)} & \sigma_{z z}^{(2)}
\end{array}\right) \\
& =\left(\begin{array}{lll}
S_{11} & S_{12} & S_{16} \\
S_{21} & S_{22} & S_{26} \\
S_{61} & S_{62} & S_{66}
\end{array}\right)\left(\begin{array}{lll}
\sigma_{x x}^{(1)} & \sigma_{x x}^{(2)} & \sigma_{x x}^{(3)} \\
\sigma_{y y}^{(1)} & \sigma_{y y}^{(2)} & \sigma_{y y}^{(3)} \\
\sigma_{x y}^{(1)} & \sigma_{x y}^{(2)} & \sigma_{x y}^{(3)}
\end{array}\right)
\end{aligned}
$$

In other words,

$$
[\varepsilon]-\left[S_{z}\right]\left[\sigma_{z}\right]=[S][\sigma]
$$

The compliance matrix is solved as

$$
[\varepsilon][\sigma]^{-1}-\left[S_{z}\right]\left[\sigma_{z}\right][\sigma]^{-1}=[S]
$$

The removed term of $\varepsilon_{z Z}$ may be used for error checking of the conceptualized parameters for $\mathrm{S}_{13}, \mathrm{~S}_{32}, \mathrm{~S}_{33}$ and $\mathrm{S}_{36}$.

$$
\varepsilon_{z z}=0=S_{31} \sigma_{x x}+S_{32} \sigma_{y y}+S_{33} \sigma_{z z}+S_{36} \sigma_{x y}
$$

\section{EVALUATION OF EQUIVALENT COMPLIANCE TENSOR}

\subsection{D and 3D computation from analytical solutions}

4.1.1 Elastic moduli and Poisson's ratio of 3D model

In this section, the comparison of 2D and 3D analyses are made analytically. Since the mechanical compliance tensor is a fourth-order tensor, the variation of each mechanical property (e.g., elastic modulus, Poisson's ratio) can be readily evaluated by transforming the tensor using equation (3). The geometry of the model is the same as in Figure 1 with spacing of $0.5 \mathrm{~m}$ and elastic modulus and Poisson's ratio of intact rock were 84.6 GPa and 0.24, respectively. Three fracture sets were considered with normal stiffness and shear stiffness as $434 \mathrm{GPa} / \mathrm{m}$ and $43.4 \mathrm{GPa} / \mathrm{m}$, respectively. Figure 6 shows the variation of elastic moduli in different orientations in 3D. The distance from the center of the solid block to the surface corresponds to the magnitude of the equivalent elastic modulus and the direction from the center to the surface correspond the direction of elastic modulus measurement. The largest and smallest elastic moduli shown in the figure correspond to around $61 \mathrm{GPa}$ and $23 \mathrm{GPa}$, respectively. The maximum value occurs in $\mathrm{x}, \mathrm{y}$, and $\mathrm{z}$ axes direction because fractures exist normal to these axes. Isotropic rock would show a complete sphere and substantial change of elastic modulus with change of orientation for anisotropic rock is evident in the figure as the six-legged structure.

Variations of normalized elastic modulus with respect to the choice of planes are shown Figure 7. Figure 7 (a) shows the case when model planes are perpendicular

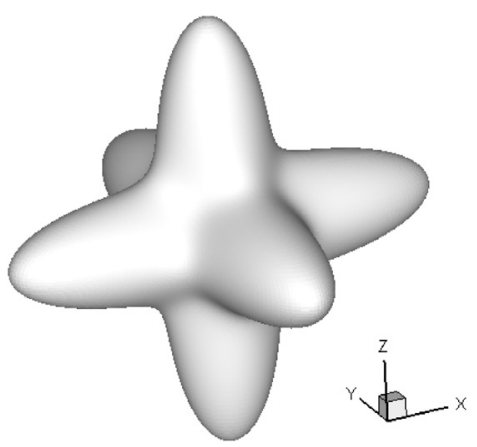

Fig. 6. 3D variation of elastic modulus of orthogonally fractured rock shown in Figure 1 


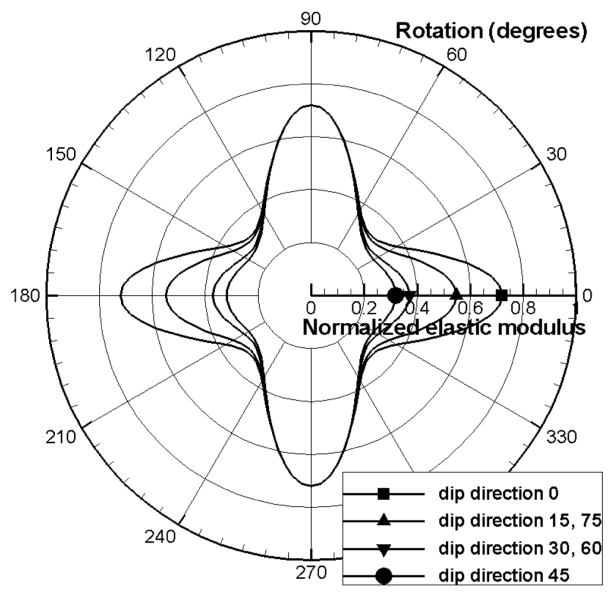

(a)

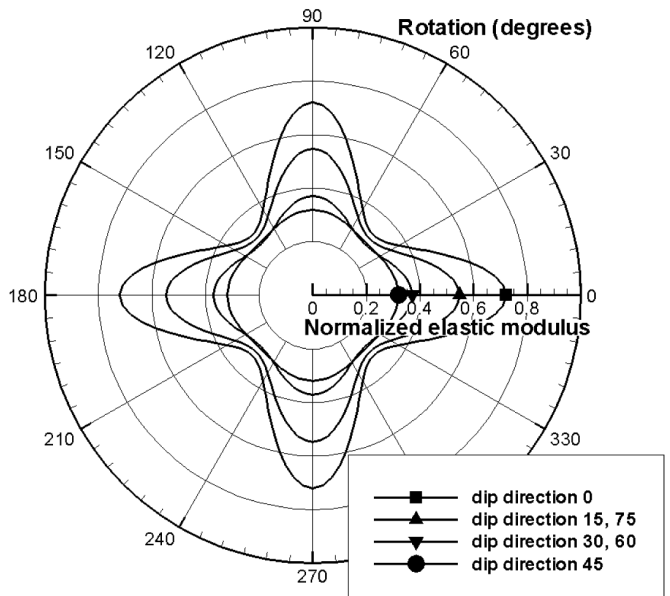

(b)

Fig. 7. Normalized elastic modulus of orthogonally fractured rock masses: (a) rotation in perpendicular plane, (b) rotation in inclined plane

to the xy-plane and elastic moduli were measured by rotating the model plane along z-axis. As shown in the figure, elastic moduli experience a substantial change in a given model plane while the elastic moduli in the vertical direction remain constant. Figure 7 (b) shows the case when the model plane is dipped 45 degrees and its dip-direction is changed up to 90 degrees in 15 degrees intervals (Figure 7 (b)). Notable observation is that when the model plane is rotated 45 degrees, the values are significantly lower than in other models and the degree of anisotropy is smaller. Similarly, Poisson's ratio $\left(v_{\mathrm{xy}}\right)$ can be investigated. Figure 8 shows Poisson's ratio in 3D form in the same geometry. Again, the distance from the center of the solid block to the surface corresponds to the magnitude of the Poisson's ratios and the direction from the center to the surface correspond the direction of loading. The largest and smallest Poisson's ratios shown in the figure correspond to around 0.63 and 0.08 , respectively. It is noted that Poisson's ratio can be larger than 0.5 for anisotropic material (Min and Jing, 2004). Figure 9 shows Poisson's ratio in the $2 \mathrm{D}$ model plane. It is evident that Poisson's ratios are also dependent on the selection of the model plane.

These results demonstrate that $2 \mathrm{D}$ analysis is dependent on the selection of the model plane that was cut from true 3D geometry.

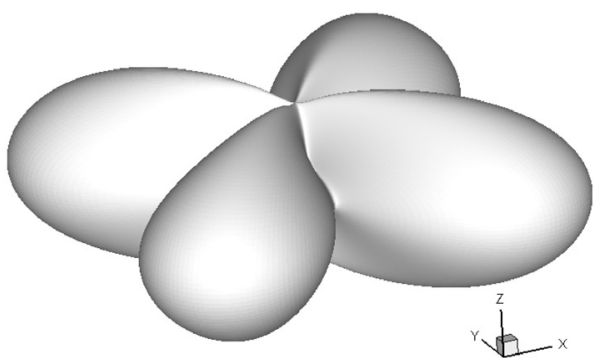

Fig. 8. Poisson's ratio of orthogonally fractured rock in three-dimensional form

\subsubsection{Comparison of $2 D$ and $3 D$ analysis}

Comparison of 2D and 3D analysis was made using the analytical solution. Figure 10 shows three models for the study. Each model is rotated around the z-axis. For case 1, 2D and 3D analysis show identical results when the model is rotated around the z-axis. This is due to the fact that 2D analysis implicitly assumes that the model plane and fracture plane are a exactly perpendicular each other, and this assumption is still valid in the $3 \mathrm{D}$ model, as can be seen in case 1 .

In case 2, however, the original model is rotated in such a way that the dip direction of the front face is 45 degrees, as compared to 0 degree in case 1 . In this case, the assumption of $2 \mathrm{D}$ analysis is no longer valid and there must be some errors when we perform 2D analysis because fractures in 3D are not perpendicular 


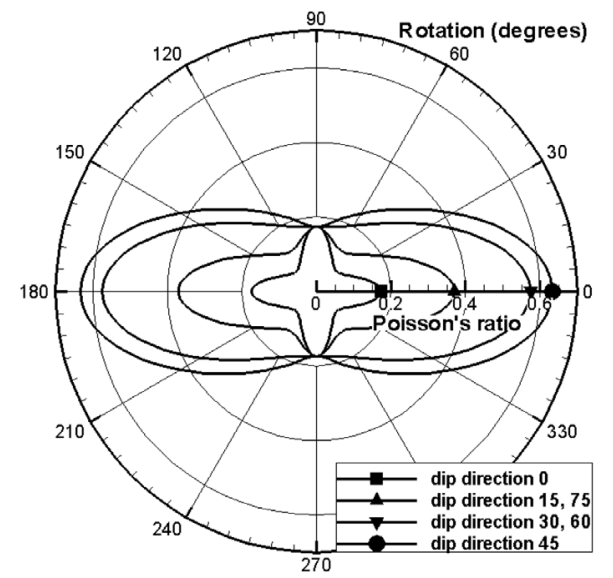

(a)

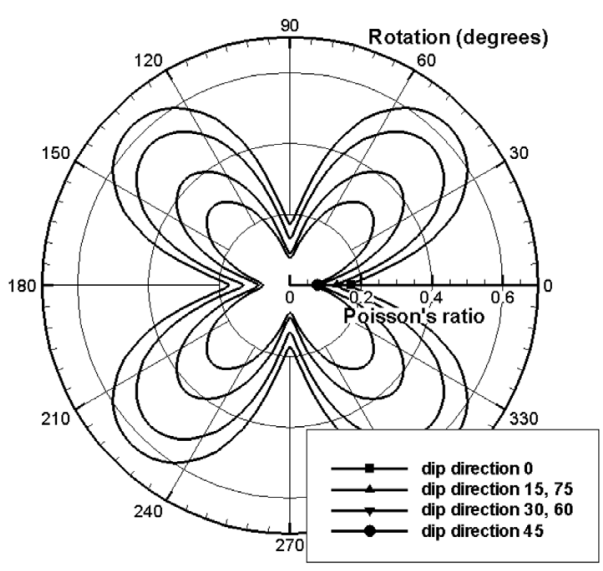

(b)

Fig. 9. Poisson's ratio of orthogonally fractured rock: (a) rotation in perpendicular plane, (b) rotation in inclined plane

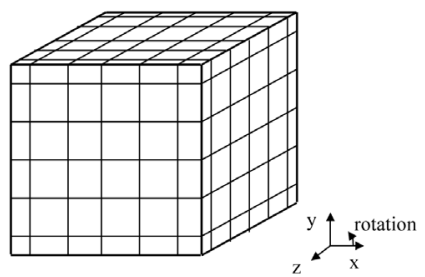

(a) Case 1
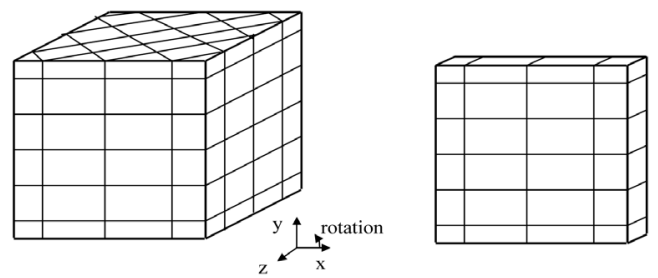

(b) Case 2
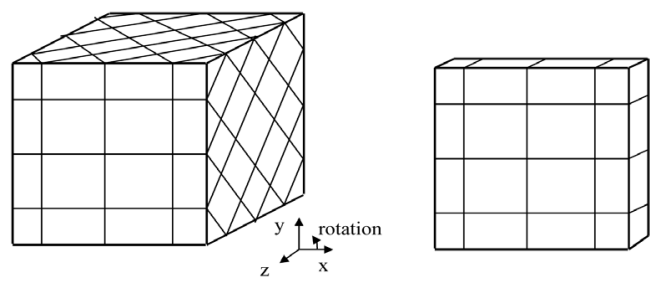

(c) case 3

Fig. 10. Three models for the comparison of $2 \mathrm{D}$ and $3 \mathrm{D}$ analyses. 3D models and 2D conceptual models are shown. (a) Original model (front reference face, dip: $90^{\circ}$, dip direction $0^{\circ}$ ), (b) Model after rotation (front reference face, dip: $90^{\circ}$, dip direction $45^{\circ}$ ), (c) Model after rotation (front reference face, dip: $45^{\circ}$, dip direction $45^{\circ}$ ) to the 2D model plane. Similarly, in case 3 , the original model is rotated in such a way that the both dip and dip direction of the front face are 45 degrees. It is anticipated that there can will even bigger errors in this case.

Figure 11 and Figure 12 show the normalized elasticmodulus and Poisson's ratio calculated by $2 \mathrm{D}$ and $3 \mathrm{D}$ analysis. Elastic moduli are always overestimated by 2D analysis because 2D geometry only consider the stiffest case in $3 \mathrm{D}$ geometry as was demonstrated in Figure 10 (b) and (c).

Poisson's ratio tends to be overestimated by 2D analysis, except for some ranges of rotation angles in case 2. In case 3, Poisson's ratio shows a consistent overestimation because of the exaggerated sliding in lateral direction in $2 \mathrm{D}$.

This analysis on orthogonally fractured model shows that the limitations of $2 \mathrm{D}$ approximation must be properly considered.

\subsection{D and 3D Numerical Experiments on Discrete Fracture Network}

Stiffness tensor $T_{i j k l}$ has been first determined with and without prolongation of the joint to the next joint, while all of the cutting planes generated by $3 \mathrm{DEC}$ are assumed to be active. The results at 5-m scale are shown in Figure 13 together with 2D results. Results at different scales of $2 \mathrm{~m}, 3 \mathrm{~m}, 4 \mathrm{~m}$, and $5 \mathrm{~m}$ of side length of 


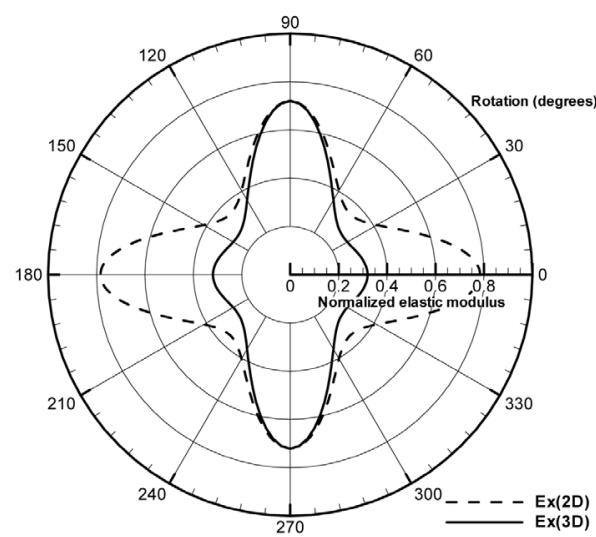

(a) normalizedelastic modulus

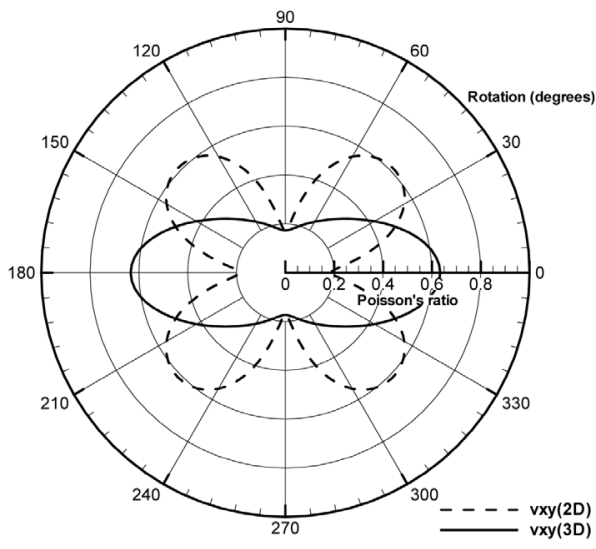

(b) Poisson's ratio

Fig. 11. Mechanical properties calculated by 2D and 3D analysis. Case 2 (dip $90^{\circ}$ and dip direction $45^{\circ}$ )

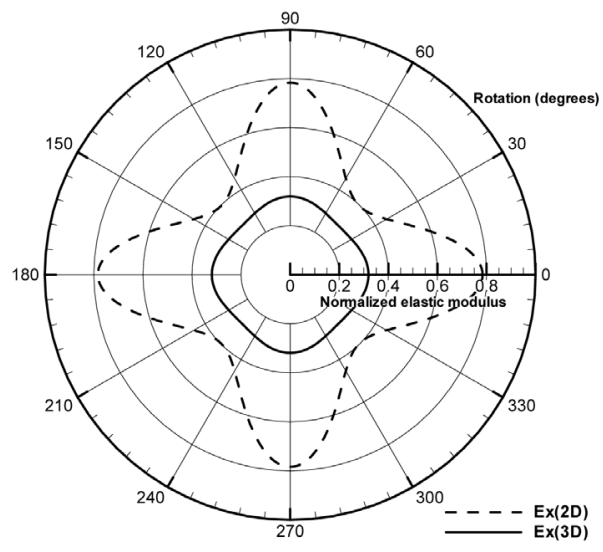

(a) Normalized elastic modulus

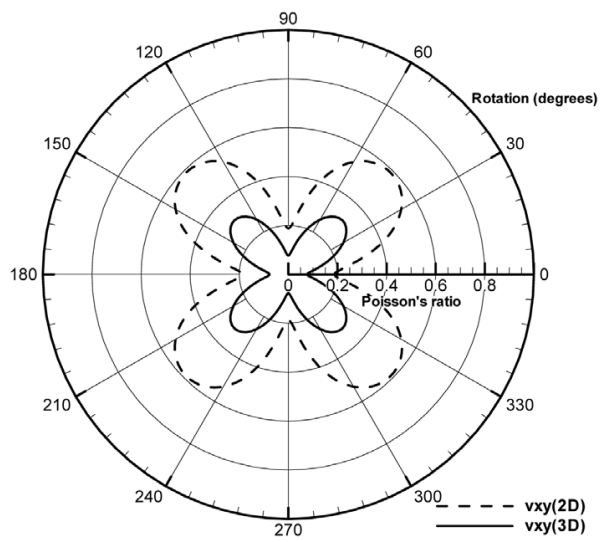

(b) Poisson's ratio

Fig. 12. Mechanical properties calculated in 2D and 3D analysis. Case 3 (dip $45^{\circ}$ and dip direction $45^{\circ}$ )

cubic model were compared, and the differences were determined to be below $10 \%$. Calculated stiffness matrix, which is an inverse matrix if compliance matrix, is as follows in the unit of GPa.

$$
\left(\begin{array}{cccccc}
39.84 & 18.55 & 18.93 & -3.15 & -2.83 & 0.30 \\
18.68 & 41.16 & 18.05 & -4.53 & 0.87 & -4.60 \\
19.31 & 18.25 & 32.78 & 0.33 & 0.31 & 0.56 \\
-1.55 & -2.27 & 0.22 & 19.94 & -0.63 & 0.76 \\
-1.37 & 0.46 & 0.23 & -0.69 & 17.16 & -0.47 \\
0.15 & -2.35 & 0.34 & 0.71 & -0.40 & 15.74
\end{array}\right)
$$

Elastic moduli in cross-sections cut along the $\mathrm{x}-, \mathrm{y}-$ and z-axes are shown in Figure 13. The values are normalized with respect to the elastic modulus of intact rock (84.6 GPa). The normalized elastic moduli are about 40 to $70 \%$ of intact rock, and some changes were observed with the selection of model plane. Considering that the elastic modulus in the 3D approach was about 24\% to $33 \%$, the elastic modulus in the $2 \mathrm{D}$ approach was much higher. The reason for this observation is the same as the case with orthogonal fracture sets. 2D approach implicitly assumes that fractures are perpendicular to the model plane, which is the stiffest possible case in a given 3D model.

Poisson's ratios in cross-sections cut along $\mathrm{x}-, \mathrm{y}-$ and $\mathrm{z}$-axes are shown in Figure 14. For Poisson's ratio $v_{\mathrm{xy}}$ 


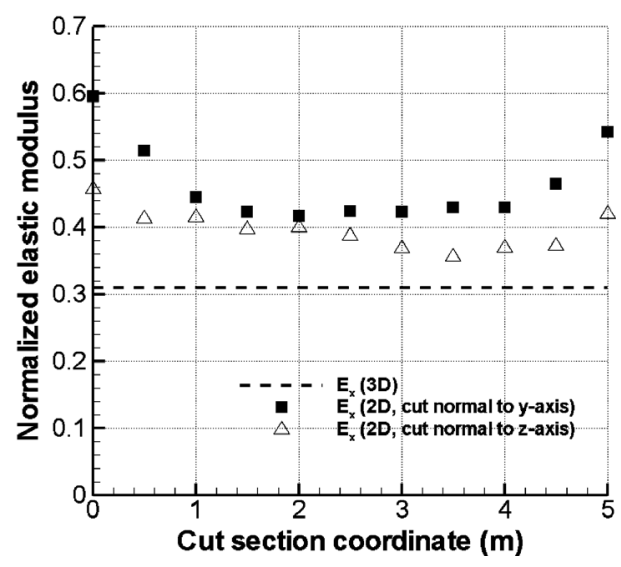

(a)

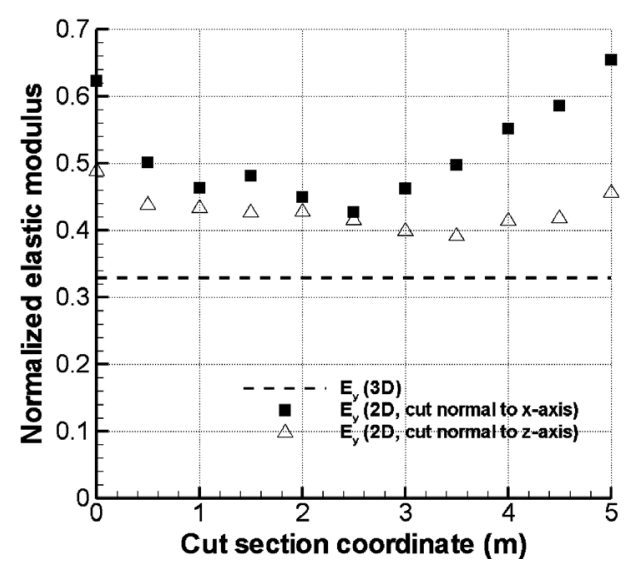

(b)

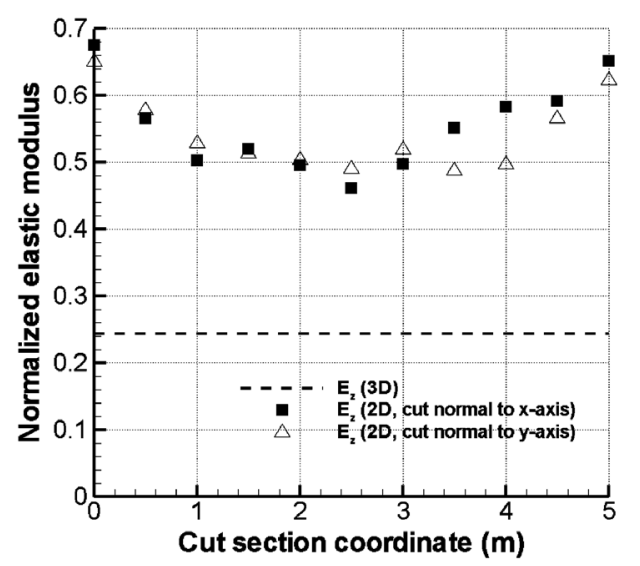

(c)

Fig. 13. Normalized elastic moduli in $3 D$ and $2 D$. (a) $x-$ direction, (b) y-direction, (c) z-direction. 2D cross sections were cut normal to $\mathrm{x}-$, $\mathrm{y}$ - or z-axes in 0.5 $\mathrm{m}$ intervals

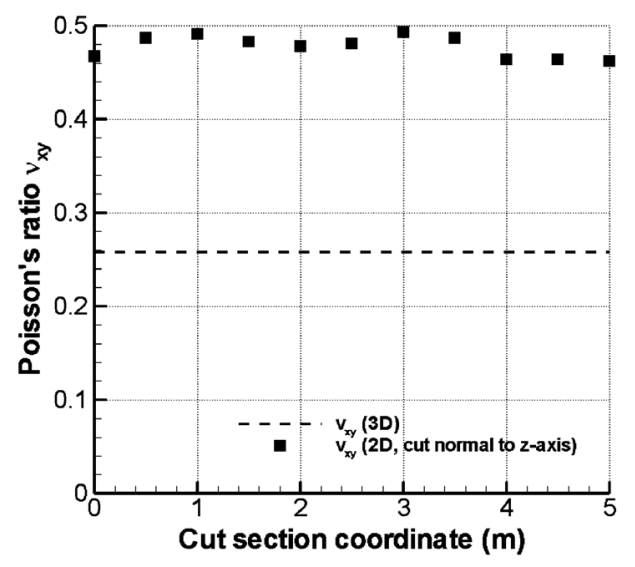

(a)

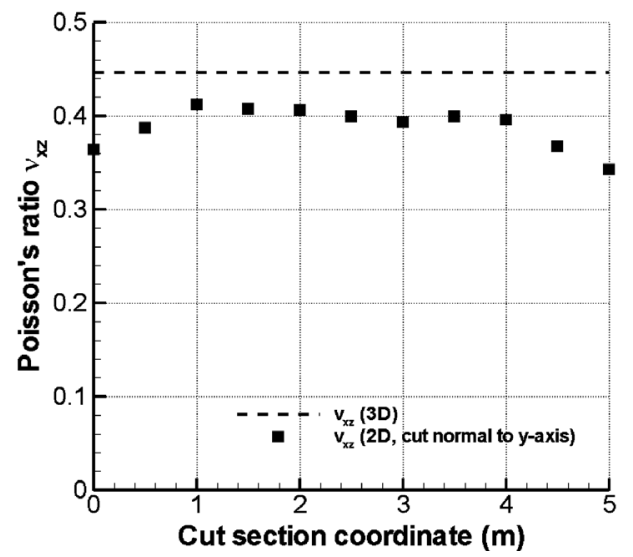

(b)

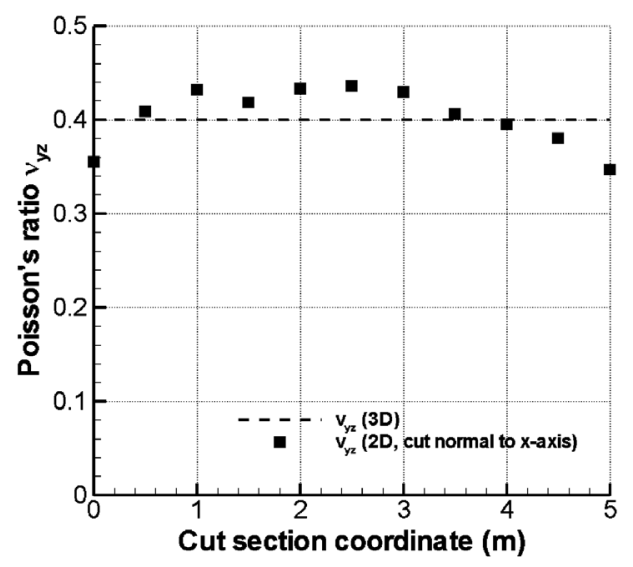

(c)

Fig. 14. Poisson's ratio in $2 D$ and $3 D$. (a) $v_{x y}$, (b) $v_{x z}$, and (c) $v_{y z}$. cross-sections cut along the $x-, y-$ and z-axes. $2 \mathrm{D}$ cross sections were cut normal to $\mathrm{x}-, \mathrm{y}-$ or $\mathrm{z}$-axes in $0.5 \mathrm{~m}$ intervals 
which is defined as the ratio of $y$-directional strain to $\mathrm{x}$-directional strain under $\mathrm{x}$-directional loading, 2D computation showed much greater values that $3 \mathrm{D}$ computation. However, somewhat mixed results were obtained for Poisson's ratios $v_{x z}$ and $v_{y z}$. Further study is needed in order to unveil the exact mechanism of Poisson's ratio variation in fractured rock mass.

\section{CONCLUSION}

This paper compares the $2 \mathrm{D}$ and $3 \mathrm{D}$ approaches in order to evaluate the limitations of the 2D approach in terms of the numerical determination of the mechanical properties of a fractured rock mass. The results show the quantified error involved in applying 2D approximation for the determination of equivalent properties of fractured rock masses. In equivalent anisotropic medium, mechanical properties vary depending on the model plane.

2D computation is conducted assuming that the fractures are perpendicular to the model plane. In general, this overestimates the elastic modulus. Poisson's ratio is overestimated or underestimated depending on the orientation of the cut plane. From the investigations of the analytical solution, it was shown that there are more chances for overestimation in a $2 \mathrm{D}$ model.

In DFN models, it is shown that elastic moduli calculated by $2 \mathrm{D}$ calculation are bigger than those calculated by 3D calculation. In many cases, the differences were more than a factor of two. There were differences in terms of Poisson's ratio, and very high Poisson's ratios in the $2 \mathrm{D}$ calculation were not consistently observed in the $3 \mathrm{D}$ calculation.

This study quantitatively demonstrated the limitations of the $2 \mathrm{D}$ approach for the determination of equivalent mechanical properties of fractured rock mass. Further work is possible by extending the current approach for the calculation of equivalent permeability.

\section{ACKNOWLEDGEMENT}

This research was supported by Basic Science Research Program through the National Research Foundation of Korea (NRF) funded by the Ministry of Education,
Science and Technology (2010-0025206). We also thank the anonymous reviewers for their helpful comments.

\section{REFERENCES}

1. Amadei, B. and R.E. Goodman, 1981, A 3-D constitutive relation for fractured rock masses, In Selvadurai APS (Ed), Proc. Int Symp on the mechanical behavior of structured media, Ottawa, Part B, 249-268.

2. Barton, N., 2002, Some new Q-value correlations to assist in site characterization and tunnel design, Int. J. Rock. Mech. Min. Sci.39.2, 185-216.

3. Bieniawski, Z.T., 1978, Determining rock mass deformability: Experience from case histories, Int. J. Rock. Mech. Min. Sci.\&Geomech. Abstr.15.5, 237-247.

4. Damjanac, B., 1994, A three-dimensional numerical model of water flow in a fractured rock mass, Ph.D. Thesis, University of Minnesota.

5. Heliot, D., 1988. Generating a Blocky Rock Mass, Int. J. Rock. Mech. Min. Sci.\&Geomech. Abstr.25.3, 127-138.

6. Hoek, E. and E.T. Brown, 1997, Practical estimates of rock mass strength, Int. J. Rock. Mech. Min. Sci.34.8, $1165-1186$

7. Itasca Consulting Group, 1994, 3DEC 3-Dimensional Distinct Element Code, Minnesota.

8. Itasca Consulting Group, 2000, UDEC user's guide, Minnesota.

9. Johansson, E., M. Hakala, E. Peltonen, J.-P. Salo and L.J. Lorig, 1991, Comparisons of computed two- and threedimensional thermomechanical response of jointed rock, $7^{\text {th }}$ ISRM Congress, 115-119.

10. Lekhnitskii, S.G., 1963, Theory of elasticity of an anisotropic elastic body, Holden Day, Inc. San Francisco.

11. Martin, D., P.K. Kaiser and R. Christiansson, 2003, Stress, instability and design of underground excavations, Int. J. Rock Mech. Min. Sci.40.7-8, 1027-1047.

12. Min, K.-B. and L. Jing, 2003, Numerical determination of the equivalent elastic compliance tensor for fractured rock masses using the distinct element method, Int. J. Rock Mech. Min. Sci.40.6, 795-816.

13. Min, K.-B. and L. Jing, 2004, Stress dependent mechanical properties and bounds of Poisson's ratio for fractured rock masses investigated by a DFN-DEM technique, Int. J. Rock Mech. Min. Sci.41.3, 431-432.

14. Min, K.-B. and O. Stephansson, 2011, The DFN-DEM Approach applied to investigate the effects of stress on mechanical and hydraulic rock mass properties at Forsmark, Sweden, J. Korean Society for Rock Mech., Tunnel and Underground Space, 21.2, 117-127.

15. Thoraval, A. T. and V. Renaud, 2003, Hydro-mechanical upscaling of a fractured rockmass using a 3D numerical approach, GeoProc 2003, Int. Conf. Coupled THMC processes in Geosystems, Stockholm, 263-268. 


\section{민 기 복}

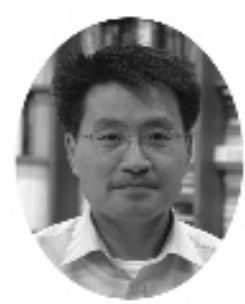

1994년 서울대학교 자원공학과 공학사 1999년 서울대학교 자원공학과 공학석사 2004년 스웨덴 왕립공과대학(Royal Institute of Technology) 공학박사

Tel: 02-880-9074

E-mail: kbmin@snu.ac.kr 현재 서울대학교 에너지자원공학과 조 교수

\section{Alain Thoraval}

1988년 Ecole des Mines de Nancy, 공 학사

1989년 Institut National Polytechnique de Lorraine de Nancy (INPL-Nancy), 공학석사(암석역학)

Tel: +33 $3 \quad 83 \quad 584290$

E-mail: alain.thoraval@ineris.fr 현재 프랑스 국립산업환경연구원 (INERIS) 그룹리더 